\title{
Too much of a good thing: Curvilinear effect of positive affect on proactive behaviors
}

\author{
CHAK FU LAM ${ }^{1 *}$, GRETCHEN SPREITZER ${ }^{2}$ AND CHARLOTTE FRITZ ${ }^{3}$ \\ ${ }^{1}$ Suffolk University, Boston, Massachusetts, U.S.A. \\ ${ }^{2}$ University of Michigan, Ann Arbor, Michigan, U.S.A. \\ ${ }^{3}$ Portland State University, Portland, Oregon, U.S.A.
}

\begin{abstract}
Summary Current organizational theory and research affirm the beneficial effects of experiencing positive affect at work. In recent years, researchers have begun to question the popular notion that the more positive affect at work, the better-that more positive affect is desirable for work-related outcomes. In this article, we propose a rationale for why more positive affect may not be better for proactive behaviors at work. Findings from two field studies using two unique data sources demonstrate support for our hypothesis, suggesting that intermediate levels of positive affect are most beneficial for proactive behaviors. Copyright (C) 2013 John Wiley \& Sons, Ltd.
\end{abstract}

Keywords: positive affect; proactive behaviors

\section{Introduction}

In today's fast-paced, uncertain, and increasingly interdependent world (Grant \& Parker, 2011), work organizations rely on their employees to be proactive in enabling the organization to run more effectively (Frese, Fay, Hilburger, Leng, \& Tag, 1997). Organizations need employees to take initiatives and be proactive, no matter their place in the organizational hierarchy. By proactive behaviors, we refer to "anticipatory actions that employees take to impact themselves and/or their environments" (Grant \& Ashford, 2008, p. 4), which include behaviors such as feedback seeking (Ashford \& Cummings, 1983), voice (Van Dyne \& LePine, 1998), issue selling (Dutton \& Ashford, 1993), and taking charge (Morrison \& Phelps, 1999; Crant, 2000; Frese \& Fay, 2001; Griffin, Neal, \& Parker, 2007; Parker, Williams, \& Turnver, 2006). The benefits of proactive behaviors on individual and group-level performance are well-documented (Parker $\& \mathrm{Wu}$, in press). For example, employees with higher proactive personality are more likely to be promoted (Seibert, Kraimer, \& Crant, 2001), and those who proactively seek information and build relationships with superiors are more likely to perform better and be more satisfied at work (Ashford \& Black, 1996). In terms of organizational outcomes, proactive individuals who speak up to benefit their customers are perceived to offer better service (Lam \& Mayer, in press), and proactive planning by business owners is associated with greater business size and objective evaluation of business success (Frese et al., 2007).

Given that proactive behaviors matter to individual and organizational performance, scholars have focused on examining factors that contribute to proactive behaviors at work. One antecedent particularly important for proactive behaviors appears to be the experience of positive affect at work (Bindl, Parker, Totterdell, \& Hagger-Johnson, 2012; Parker, Bindl, \& Strauss, 2010; Parker \& Wu, in press). For example, Den Hartog and Belschak (2007) found a positive relationship between positive trait affect and personal initiative. Likewise, Fritz and Sonnentag (2009) found support for a positive relationship between positive affect during the workday and self-reported proactive behaviors on the same day and the following workday. In a recent day-level study, Bissing-Olson, Iyer, Fielding, and Zacher (2013) found that daily positive affect is associated with more pro-environmental proactive behaviors for those who generally do not hold a positive pro-environmental attitude.

\footnotetext{
*Correspondence to: Chak Fu Lam, Suffolk University, 8 Ashburton Pl, Boston, MA 02108, U.S.A. E-mail: cflam@ suffolk.edu
} 
In this article, we seek to examine the relationship between positive affect and proactive behaviors in more depths. Specifically, we build on recent psychological research that suggests that "people can get too much of a good thing, experiencing a downturn in good outcomes with disproportionate levels of positive emotion" (Fredrickson, 2013, July 15). Prior research has found such a nonlinear relationship between positive emotions and political participation (Oishi, Diener, \& Lucas, 2007), risky behaviors (Martin et al., 2002), accumulated relational resources (Waugh \& Fredrickson, 2006), and creativity (Rego, Sousa, Marqes, \& Cunah, 2012). To build on the idea of no such thing as "an unmitigated good," Grant and Schwartz (2011, p. 62) suggested that future research needs to identify the prevalence and inflection points of these nonlinear effects. Drawing from broaden-and-build theory (Fredrickson, 2001) and affect-as-information theory (Carver, 2003; Schwarz \& Clore, 1983, 2003), we posit that the relationship between positive affect and proactive behaviors may be more complicated than a simple linear relationship. Specifically, we hypothesize that too little or too much positive affect can hamper proactive behaviors at work (i.e., a curvilinear relationship). In the following sections, we develop our hypothesis and then draw on two samples to test them empirically.

\section{Theory and Hypothesis}

In recent reviews of the proactivity literature, Parker and colleagues (Parker et al., 2010; Parker $\& \mathrm{Wu}$, in press) proposed three motivational pathways to explain why employees engage in proactive behaviors. The first pathway, called the "can do" pathway, concerns employees' feeling of efficacy to engage in proactive behaviors. Parker and colleagues asserted that proactive behaviors are more likely when employees believe that they are capable of influencing their work environment, to cope with potential setbacks, and to perceive a high likelihood of success in engaging in proactive behaviors (Ashford, Rothbard, Piderit, \& Dutton, 1998; Raub \& Liao, 2012). Supporting this view, scholars have shown that the experience of "can do" is a key determinant of proactive behaviors (Parker et al., 2006; Stajkovic \& Luthans, 1998). The second pathway is called the "reason to" pathway. In order for employees to engage in proactive behaviors, they must perceive that there are reasons to engage in these behaviors (Morrison \& Phelps, 1999; Parker, Wall, \& Jackson, 1997; Tangirala \& Ramanujam, 2008). Research has shown that those who are dedicated to benefit the recipients of proactive behaviors (e.g., peers, customers, work units, or organization) are more likely to engage in proactive behaviors (Lam \& Mayer, in press; Tangirala \& Ramanujam, 2008). Thus, the importance of these two motivational pathways is well-established (Parker \& $\mathrm{Wu}$, in press).

Whereas the "can do" and "reason to" pathways are cognitive mechanisms through which employees are motivated to engage in proactive behaviors, the third motivational pathway, termed the "energized to" pathway, is an affective mechanism that has garnered attention only in recent years. Parker and colleagues suggest that the experience of positive affect is particularly conducive to proactive behaviors, because positive affect "expands thinking and results in more flexible cognitive processes" and "invokes feelings of energy" (Parker \& Wu, in press, p. 6). In support of this assertion, Den Hartog and Belschak reported that hospital employees who exhibited a greater level of positive affect were more likely to engage in proactive behaviors, and Fritz and Sonnentag (2009) showed that positive affect during the day was positively associated with proactive behavior on the same and the following day. Perhaps the most important evidence that positive affect is linearly and positively associated with proactive behavior is reported by Bindl et al. (2012), who surveyed 225 employees working for a U.K. multinational organization in a call center and 250 first year undergraduate students in a British medical school. Across both studies, the authors found that positive affect was positively associated with all elements of self-reported proactivity: envisioning the future, planning to execute change, enacting change, and reflecting changes that have occurred. In sum, these research studies seem to suggest that the relationship between positive affect and proactive behaviors is a positive and linear one.

In this article, we suggest that the relationship between positive affect at work and proactive behaviors may not be so simple, as past research has neglected a possible curvilinear relationship. Two theories help build our argument. The first theory of positive affect is the broaden-and-build theory (Fredrickson, 1998, 2001), which suggests that 
positive affect can help enhance flexible thinking (Derryberry \& Tucker, 1994) and encourage individuals to focus on new possibilities and opportunities rather than constraints (Kimchi, 1992). In addition, positive affect can also enhance one's action tendencies that lead to favorable outcomes (Kaplan, Bradley, Luchman, \& Haynes, 2009). Finally, the broadening of people's cognition and action tendencies can be cumulative and help people build cognitive (e.g., increased mindfulness), psychological (maintaining a sense of mastery over challenges), and social (e.g., psychological safety and social support) resources over time (Fredrickson, 2001; Fredrickson, Cohn, Coffey, Pek, \& Finkel, 2008).

A second theory of positive affect is known as affect-as-information theory (Carver, 2003; Schwarz \& Clore, 1983, 2003). According to this theory, individuals use their feelings as information to form judgments about how to respond to their environment. Positive affect signals that things are generally going in the right direction and the environment is free of major issues or problems. As a result, individuals may believe that they do not need to initiate change in their work environment-that there is no need to "rock the boat" by introducing something new. By contrast, less positive feelings may signal that improvements are necessary (Clore, Schwarz, \& Conway, 1994; Schwarz, 1990). When individuals are not experiencing high levels of positive affect, they are likely to recognize more opportunities to improve the situation to make it better and help them feel more positive (Foo, Uy, \& Baron, 2009).

Integrating broaden-and-build theory and affect-as-information theory, we propose a nonlinear relationship between positive affect at work and proactive behaviors. At low levels of positive affect at work, employees' ability to think broadly and to identify innovative solutions for issues and concerns at work are significantly reduced. Furthermore, low levels of positive affect are likely to hamper employees' ability to build cognitive resources (e.g., the capability to anticipate and plan in advance), psychological resources (e.g., the sense of efficacy to engage in proactive behaviors), and social resources (e.g., the interpersonal connections that make change possible) over time. Limited resources, in turn, make it difficult for employees to engage in proactive behaviors, as individuals feel that they do not have the necessary resources to be proactive. Therefore, at low levels of positive affect at work, employees are less likely to engage in proactive behaviors. As positive affect at work reaches an intermediate level, employees are relatively more likely to experience broadened cognition, exhibit greater action tendency, and accumulate more cognitive, social, and psychological resources to engage in proactive behaviors. Therefore, we expect that moderate levels of positive affect will result in more proactive behaviors than low levels of positive affect.

As positive affect at work further increases to a high level, however, the affect-as-information mechanism begins to take over. Although employees experiencing high levels of positive affect at work experience broadened cognitions, enhanced action tendencies, and increased resources, they are also more likely to perceive that things are going well and there is little need to be proactive to initiate changes in the workplace. The higher levels of positive affect may create a kind of contentment or even complacency. This assertion is consistent with research on unrealistic optimism (Weinstein, 1980; Weinstein \& Klein, 1996), which suggests that individuals tend to underestimate the probability of negative events happening to them, especially when they feel highly positive and optimistic about the future. Therefore, even if employees believe that they can effectively alter or change their work environment because of the broaden-and-build effect, their experience of high levels of positive affect may signal to them that it is not important or urgent to engage in change behaviors at the present time. As such, we expect that employees with high levels of positive affect at work feel less need to engage in proactive behaviors.

In sum, we expect that the relationship between positive affect and proactive behavior will take the form of an inverted-U relationship. When positive affect is low, individuals experience narrowed cognition, reduced action tendency, and lack resources for proactive behaviors. As positive affect increases to a moderate level, individuals are able to think in a more flexible manner and will feel greater action tendency to engage in proactive behaviors, but not so much positive affect that may result in underestimating the importance of proactive behaviors. After a certain point, however, positive affect can reach a level such that employees perceive that they are doing well and are not necessary for them to take initiatives, thereby reducing their proactive behaviors. Therefore, we hypothesize the following: 
Hypothesis 1: The relationship between positive affect at work and proactive behaviors will exhibit a curvilinear, inverted-U relationship, such that positive affect at work is positively related to proactive behaviors to a point; beyond this point, the relationship between positive affect at work and proactive behaviors becomes negative.

We conducted two studies to test our hypothesis, with the second study addressing some of the empirical limitations of the first. Across both studies, we used supervisory ratings of employee proactive behaviors to reduce concerns regarding common method bias and to better understand the relationship between positive affect and proactive behaviors at work.

\section{Study 1}

\section{Participants and procedure}

We invited 400 employees in a U.S. software development firm to participate in the study. Employees were knowledge workers and staff who worked across hierarchical levels. We first asked each participant to indicate their positive affect at work as well as their basic demographics. In order to protect the anonymity of the participants, we asked each of them to send a self-generated, five-digit code together with an online link to their immediate supervisors, who then provided information about the participants' proactive behaviors. We thanked both participants and their supervisors with a $\$ 5$ gift card. Of the 400 employees we invited, we collected a total of 236 responses, and we were able to match 102 responses from their supervisors, representing a 25.5 percent final response rate.

Forty-four percent of the participants were female, and their mean age was 46.3 years $(S D=8.61)$. They had worked at the organization for an average of 12.0 years $(S D=7.34)$, spent a mean of 41.0 hours at work each week $(S D=8.39)$, and the majority of them (72.1 percent) occupied a non-supervisory role. In addition, 75.6 percent of the participants had obtained a college degree or above. They worked in various departments of the organization, with the majority of them in the solutions and analytics testing division (20.7 percent), research and development business operations (12.6 percent), and product planning and release coordination (11.7 percent). Among those who participated but whose supervisors did not provide ratings of proactive behaviors, 50 percent were female and their mean age was 41.57 years $(S D=10.11)$. These participants had worked at the organization for an average of 10.33 years $(S D=7.15)$, spent a mean of 41.49 hours at work $(S D=7.73)$, and 71.0 percent occupied a non-supervisory role. Similar to those who have participated and who have ratings of proactive behaviors, 94 percent of the participants had obtained a college degree or above, and worked in various departments of the organization (solutions and analytics testing division-21.1 percent; research development business operations-12.8 percent; and product planning and release coordination-11.0 percent). Finally, we conducted a non-response analysis to examine whether there were any differences between participants whose supervisors provided ratings of proactive behaviors and those whose supervisors did not provide ratings. We found no significant differences in terms of gender $(F=.72, p<.40)$, educational level $(F=2.58, p<.11)$, tenure at the participating organization $(F=2.62, p<.11)$, and positive affect at work $(F=1.77, p<.18)$. However, there was a significant difference in age $(F=12.94, p<.00)$, with a higher likelihood of managerial response provided to those who were older. One possible explanation for the significant difference is that older employees may have longer, more established relationship with their supervisors. As a result, supervisors find it easier to provide ratings to those whom they have an established relationship.

\section{Measures}

Unless otherwise stated, all variables were assessed using a seven-point Likert scale ( $1=$ strongly disagree; $2=$ disagree; 3 = slightly disagree; $4=$ neither agree nor disagree; $5=$ slightly agree; $6=$ agree; $7=$ strongly agree). 


\section{Positive affect at work}

We assessed positive affect at work using Ryan and Frederick's (1997) seven-item measure of subjective vitality, adding the phrase "at work" to the end of each item (Shaffer \& Postlethwaite, 2012). We choose the subjective vitality as a measure of positive affect as work for two reasons. First, from a theoretical perspective, Parker and colleagues conceptualized the "energized to" pathway as an exclusively affective process (Parker \& Wu, in press). Similarly, subjective vitality is defined as a positive feeling of aliveness and energy; it is a state of hedonic, pleasant experience that is akin to the type of positive affect described by Parker and Wu. Other related but somewhat different measures of positive affect, such as vigor (Shirom, 2003), is a broader construct that includes physical strength and cognitive liveliness. Therefore, the experience of subjective vitality is conceptually similar to the feeling of positive affect described by Parker et al. (2010). Second, from a methodological positive, the type of positive affective experiences described by Parker et al. (2010) such as enthusiasm, excitement, and emotional energy are similar to those described by the subjective vitality scale (sample items: "I feel alive and vital at work" and "I have energy and spirit at work."). Therefore, we feel that the subjective vitality at work measure is more appropriate in capturing one's experience of positive affect at work than other similar constructs. The subjective vitality scale has been used in psychological (Nix, Ryan, Manly, \& Deci, 1999) and organizational research (Fritz, Lam, \& Spreitzer, 2011; Porath, Spreitzer, Gibson, \& Garnett, 2012) and has demonstrated excellent reliability. Therefore, we choose the subjective vitality scale as a measure of positive affect at work. Cronbach's alpha was .89 .

\section{Proactive behaviors}

To measure proactive behaviors, we asked participants' supervisors to provide ratings of participants' voice behaviors (Van Dyne \& LePine, 1998). Voice involves raising concerns and expressing work-related issues to benefit the immediate work environment or the organization. It is considered a type of proactive behaviors (Grant \& Ashford, 2008; Grant, Parker, \& Collins, 2009), as individuals make suggestions for improvement for themselves or their workgroup, thus making self-initiated changes to impact the work environment. Thus, we asked participants' supervisors to provide ratings of proactive behaviors expression at work using Van Dyne and LePine's (1998) voice measure. Sample items include "He/she develops and makes recommendations concerning issues that affect others at work" and "He/she speaks up and encourages others at work to get involved in issues". Cronbach's alpha was .89.

\section{Control variables}

We included several demographic control variables. We asked participant's supervisors to report their number of years as a supervisor (years of supervision), as we expected that the longer the years of supervision, the greater the likelihood that a supervisor might exhibit liking to a subordinate and, as a result, a more favorable rating of proactive behaviors than those who have worked fewer years with the supervisor. In addition, we also controlled for supervisor's familiarity with the work of the subordinate (familiarity with work), because supervisors who are more familiar with the work of their subordinates are more likely to appreciate the constructiveness of proactive behaviors, thereby giving a higher rating (Whiting, Maynes, Podsakoff, \& Podsakoff, 2012). Finally, we included participants' age and gender, both of which were associated with proactive behaviors in prior research (Sonnentag, 2003).

\section{Results}

Means, standard deviations, and correlations for key study variables in Study 1 are presented in Table 1. To test our hypothesis, we conducted hierarchical ordinary least-squares (OLS) regression analyses (Table 2). We entered the control variables in Step 1, the linear term of positive affect in Step 2, and the squared term of positive affect in Step 
Table 1. Means, standard deviations, and correlations among study variables (Study 1).

\begin{tabular}{|c|c|c|c|c|c|c|c|c|}
\hline Variable & $M$ & $S D$ & 1 & 2 & 3 & 4 & 5 & 6 \\
\hline 1. Age & 46.35 & 8.58 & - & & & & & \\
\hline 2. Gender & 0.45 & 0.50 & .12 & - & & & & \\
\hline 3. Years of supervision & 3.18 & 3.04 & .09 & .08 & - & & & \\
\hline 4. Familiarity with work & 6.01 & 1.04 & .01 & .16 & $.44 * *$ & - & & \\
\hline 5. Positive affect & 4.73 & 1.16 & .18 & .17 & -.01 & -.02 & $(.89)$ & \\
\hline 6. Proactive behaviors & 4.98 & 1.24 & -.04 & .07 & .15 & $.30 * *$ & .05 & $(.89)$ \\
\hline
\end{tabular}

Note: $N=102$. Gender is coded such that female equals 1 . The Cronbach's alpha for each scale is presented on the diagonal. $* * p<.01$.

Table 2. Results of hierarchical regression models of the curvilinear effect of positive affect on proactive behaviors (Study 1).

\begin{tabular}{lcrr}
\hline & \multicolumn{3}{c}{ Proactive behaviors } \\
\cline { 2 - 4 } Variables & Model 1 & Model 2 & Model 3 \\
\hline Age & -0.07 & -0.11 & -0.11 \\
Gender & 0.05 & 0.03 & 0.05 \\
Years of supervision & 0.05 & 0.05 & 0.05 \\
Familiarity with work & $0.24 *$ & 0.18 & $0.19^{+}$ \\
Positive affect (linear) & & & 0.04 \\
Positive affect (curvilinear) & & 2.61 & $-0.35^{* * *}$ \\
$\Delta F$ & 1.78 & 0.10 & $9.83^{* * *}$ \\
$R^{2}$ & 0.08 & 0.20 \\
\hline
\end{tabular}

Note: $N=102 .{ }^{+} p<.10 ; * p<.05 ; * * * p<.001$.

3. Because the analyses involved the squared term of positive affect, we followed Aiken and West's (1991) advice on testing nonlinear relationships by centering the predictor variables (including control variables).

Our hypothesis predicted that the relationship between positive affect at work and proactive behaviors would be an inverted-U: positive affect at work contributes to more proactive behaviors up to a point; beyond that point, the relationship would become negative. In Model 1, we found that supervisor's familiarity with the work of participants was positively associated with proactive behaviors. This suggests that the more the supervisor understands the challenges of their subordinates' work, the higher the ratings of proactive behaviors. In Model 2, the linear term of positive affect was not significant $(\beta=.18, n s)$, providing the basis for examining our more nuanced predictions of a curvilinear relationship. Finally, consistent with our hypothesis (Model 3), we found that the coefficient of the squared term of positive affect was significant and negative $(\beta=-.35, p<.05)$. The inclusion of the squared term of positive affect into the equation resulted in an improvement of adjusted $R^{2}$ from 0.10 to 0.20 . A more detailed analysis showed that the inflection point occurs at 4.69 of positive affect at work (Figure 1). Thus, our hypothesis was fully supported. ${ }^{1}$

Although the finding of Study 1 was encouraging, we recognized that it might be biased because of self-selection. A threat posed by self-selection is that individuals who did not participate in the study exhibited certain behaviors that, if included, would alter the reported relationship, either in the form of under-estimation or over-estimation (Heckman, 1979). It is possible that participating in our research is itself a proactive behavior, and so, responding to our surveys may be influenced by positive affect itself. To address this concern, we estimated a selection bias

\footnotetext{
${ }^{1}$ We also empirically tested whether results would be comparable without controlling for years of supervision and supervisor's familiarity with subordinate's work. We found that when years of supervision and supervisor's familiarity with subordinate's work are not entered in the equation, the linear term of positive affect is insignificant $(\beta=-.04, n s)$, whereas the squared term of positive affect is significant $(\beta=-.30, p<.01)$.
} 


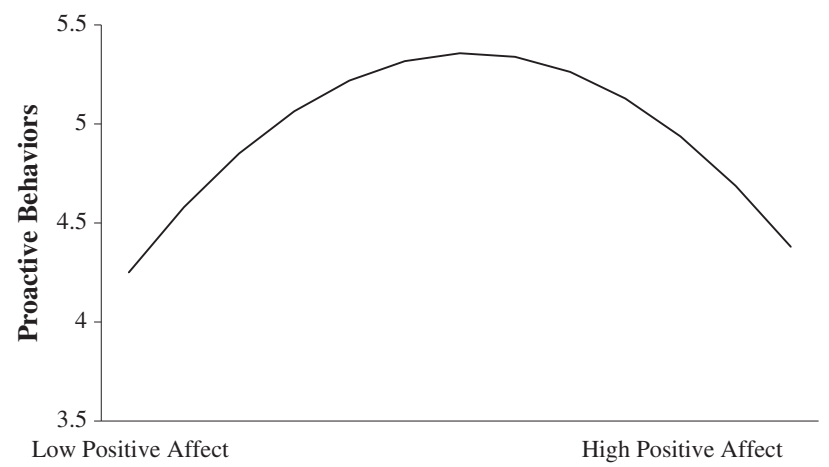

Figure 1. The curvilinear effects of positive affect at work on proactive behaviors (Study 1)

model using Heckman's (1979) two-step procedure to control for selection bias. In the first step of the Heckman procedure, the selection process that is responsible for selection bias problems is studied with the selection model. We did so by modeling the response of the supervisor (respond or not respond) using a probit equation based on the age of the subordinate. We then used the residuals of the selection equation to construct a selection bias control factor, Lambda (also known as the Inverse Mill's Ratio). This factor summarizes the effects of unmeasured characteristics that are related to positive affect. In the second step of the Heckman procedure, we re-ran our OLS regression analysis of the curvilinear effects of positive affect on proactive behaviors. In this substantive equation, we used the selection bias control factor Lambda as an additional independent variable. Because this factor reflects the effect of all the unmeasured characteristics that are related to the positive affect, the coefficient of this factor in the substantial analysis explains the part of the effect of these characteristics on proactive behaviors. In the substantive equation, we found that our results were identical after estimating the selection bias model. Specifically, the effect of the linear term of positive affect remained insignificant $(\beta=.03, n s)$, whereas the squared term of positive affect (i.e., curvilinear effect) remained significant $(\beta=-.36, p<.01)$.

\section{Study 2}

In Study 2, we sought to confirm the findings of Study 1 as well as address several limitations in its design. First, we controlled for individual differences in positive and negative affect (often termed as positive affectivity and negative affectivity; Watson, Clark, \& Tellegen, 1988). It is possible that rather than the feeling of positive affect at work being the most important affective predictor of proactive behaviors, that it is merely capturing one's individual propensity for positive or negative affect. Second, it is unclear whether the results of Study 1 would generalize to other types of individual proactive behaviors beyond voice. Thus, in Study 2, we conducted informal interviews and created a measure of proactive behaviors consistent with Grant and Ashford's (2008) and Parker et al.'s (2010) conceptualization of proactive behaviors. Third, in Study 2, we addressed limitation due to the cross-sectional design of Study 1 by using a longitudinal, prospective design. Finally, Study 2 drew on a sample of service employees to enhance the generalizability of the findings in Study 1 beyond knowledge workers.

\section{Participants and procedure}

The participating organization was a support service management company that delivered environmental and food services to hospitals, healthcare providers, long-term care facilities, continuing care retirement communities, and other 
healthcare specialty institutions. We employed a prospective design with two stages of data collection. In the first stage, we sent out an email to all participants, whose contact information was provided by the organization, and invited them to fill out the first self-report survey that included measures of the main predictor variable (affect at work) as well as control variables. Respondents received a \$5 gift card as a token of our appreciation. One month later, we contacted the participants' supervisor asking them to provide ratings of participants' proactive behaviors. Supervisors who provided ratings were also thanked with a $\$ 5$ gift card.

In total, 196 (out of possible 210) participants filled out the survey, and 128 matched responses from supervisors were obtained, representing 61.0 percent of the total sample. Participants' mean age was 49.0 years $(S D=9.55)$. About 50 percent were female. They were mostly Caucasian (75.0 percent) or African American (19.7 percent). Participants had worked at the organization for an average of 6.33 years $(S D=8.61)$ and at their current post for an average of 4.88 years $(S D=6.21)$. In addition, 24.2 percent of the participants held a high school or G.E.D. diploma, 42.1 percent some college or associate degree, 25.8 percent a college/university degree, and 7.9 percent a masters degree. We conducted a non-response analysis to examine whether there were any differences between participants with ratings of proactivity and those without. We found no significant differences in terms of gender $(F=.06, p<.80)$, age $(F=1.43, p<.23)$, educational level $(F=1.03, p<.31)$, and tenure at the participating organization $(F=1.35, p<.25)$ and at the facility $(F=.03, p<.86)$. In addition, we did not find any significant differences in terms of number of years participants had worked for their supervisors $(F=.20, p<.66)$, positive affectivity $(F=1.69, p<.20)$, negative affectivity $(F=.41, p<.52)$, and positive affect at work $(F=1.54, p<.22)$. Thus, we concluded that there was little indication of non-response bias in our data.

\section{Measures}

\section{Positive affect at work}

We employed the same measure as in Study 1. Cronbach's alpha was .85.

\section{Proactive behaviors}

To obtain a more accurate understanding and measurement of proactive behaviors in this particular setting, the first author qualitatively explored what was the most representative focus of proactive behaviors to better understand what constitutes proactivity for service supervisors. During informal interviews, a majority of the interviewees indicated that a major aspect of being proactive in their workplace was to act in advance to prevent problems related to customer service. For instance, one participant "conducted a lot of informal inspections as a way to ensure that we don't have the same problems or prevent potential problems in the future." Many other participants reiterated similar themes, such as having to "actively look for things that have gone wrong" and "talk to people from other departments and dissect the problems." These problems might be related to the patients (e.g., a particular patient has been very picky about the room even with the tiniest taint) or to other constituents in the facility (e.g., a conflict with the nursing department regarding schedule of cleaning the patient rooms).

After gaining a better understanding of what participants considered to be proactive behaviors at work, we then examined the literature on proactivity to adapt and develop items that best reflected the type of proactive behaviors informants described. We reworded items, taken from various literatures such as taking charge (Morrison \& Phelps, 1999), voice (Van Dyne \& LePine, 1998), and issue selling (Ashford et al., 1998) so that each item fit the current context. The list of items was then submitted to expert raters who had obtained or were pursuing their Ph.D. degree in Organizational Behavior to judge whether the items were consistent with the definition of proactive behaviors. Only items with the highest consensus were retained. We then invited interviewees who participated in the informal interviews to rank-order whether the items were applicable to their work. The final list of proactive items included 20 items that were very relevant for this context. 
After data were collected, we submitted all 20 items to exploratory factor analysis using the principal axis factoring extraction method to explore the underlying structure of the data. Because of the low primary loadings of several items, we retained a total of eight items that had substantial loadings (see Appendix A). The final list of eight items corroborated what we learned from the informal interview data. More specifically, the final set of items measured the extent to which participants actively anticipated, planned, and acted to prevent problems and issues for their customers. These activities include trying to correct faulty procedures before the problems become serious, as well as seeking feedback from their supervisors or other departments to ensure that there were no service complaints. Cronbach's alpha was .97. We then conducted a CFA using EQS software version 6.1 with maximum likelihood estimation procedures on the eight-item proactivity items. The expected one-factor solution displayed very good fit with the data, $\chi^{2}(54)=248.04, \mathrm{CFI}=0.96, \mathrm{RMSEA}=0.043, \mathrm{SRMR}=0.069$. All factor loadings were statistically significant and ranged from .92 to .99 .

\section{Control variables}

We included several control variables in our analyses. First, we controlled for positive affectivity and negative affectivity by using the 20 adjectives from Watson et al.'s (1988) Positive Affect (e.g., "inspired", "interested", and "determined") and Negative Affect (e.g., distressed, upset, and scared) Scale. We controlled for these variables, as past research (Den Hartog \& Belschak, 2007) suggests that trait affect may influence proactive behaviors. The Cronbach's alphas for PA and NA were .85 and .83 , respectively. We conducted a CFA with maximum likelihood estimation procedures to ensure that positive affectivity, negative affectivity, and positive affect at work were empirically distinct constructs. As shown in Table 3, the expected three-factor solution displayed good fit with the data, $\chi^{2}(321)=581.35, \mathrm{CFI}=0.96, \mathrm{RMSEA}=0.06, \mathrm{SRMR}=0.067$. All factor loadings were statistically significant and ranged from .57 to .84 for positive affectivity, .43 to .81 for negative affectivity, and .33 to .89 for positive affect at work. Alternative nested models displayed significantly poorer fit. The correlation between positive affectivity and positive affect at work was only moderate (.54), providing further support that they are distinct constructs. Thus, we concluded that positive affectivity, negative affectivity, and positive affect at work in our sample were distinct constructs. We also included a set of demographic control variables parallel to that of Study 1, including participants' age, gender, as well as supervisor-rated years of supervision, and supervisor's familiarity with work with the participants.

\section{Results}

Means, standard deviations, and correlations for study variables are presented in Table 4. All variables exhibit adequate to excellent reliability, ranging from .78 to .97 . We followed OLS regression procedures similar to that employed in Study 1 by entering the demographic and trait affect variables at Step 1, followed by the linear effect

Table 3. Factor loadings of confirmatory factor analysis of positive affectivity, negative affectivity, and positive affect at work.

\begin{tabular}{llrrrrrr}
\hline No. & \multicolumn{1}{c}{ Model } & $x^{2}$ & $d f$ & CFI & RMSEA & SRMR & $\begin{array}{c}\text { Chi-square } \\
\text { difference test }\end{array}$ \\
\hline 1 & $\begin{array}{l}\text { One-factor } \\
2\end{array}$ & 1295.67 & 324 & 0.84 & 0.16 & 0.11 & - \\
& $\begin{array}{l}\text { Two-factor (negative affectivity as } \\
\text { the first factor, and positive affectivity } \\
\text { and positive affect at work as second factors) } \\
\begin{array}{l}\text { Three-factor (positive affectivity, } \\
\text { negative affectivity, and positive } \\
\text { affect at work as three factors) }\end{array}\end{array}$ & 581.35 & 323 & 0.90 & 0.12 & 0.085 & $x^{2}(1)=362.29 * * *$ \\
\hline
\end{tabular}

Note: $* p<.05 ; * * p<.01 ; * * * p<.001$. 
Table 4. Means, standard deviations, and correlations among study variables (Study 2).

\begin{tabular}{|c|c|c|c|c|c|c|c|c|c|c|}
\hline Variable & $M$ & $S D$ & 1 & 2 & 3 & 4 & 5 & 6 & 7 & 8 \\
\hline 1. Age & 48.99 & 9.55 & - & & & & & & & \\
\hline 2. Gender & 0.51 & 0.50 & .05 & - & & & & & & \\
\hline 3. Years of supervision & 2.01 & 2.97 & $.17 *$ & $.21 * *$ & - & & & & & \\
\hline 4. Familiarity with work & 3.97 & 0.94 & -.04 & -.06 & .09 & - & & & & \\
\hline 5. Positive affectivity & 5.85 & 0.78 & -.02 & -.03 & .01 & -.08 & $(.85)$ & & & \\
\hline 6. Negative affectivity & 1.74 & 0.71 & -.07 & .06 & .04 & -.00 & $-.39 * *$ & $(.83)$ & & \\
\hline 7. Positive affect at work & 5.56 & 0.89 & .10 & -.10 & -.13 & -.07 & $.54 * *$ & $-.33 * *$ & $(.82)$ & \\
\hline 8. Proactive behaviors & 5.34 & 1.00 & $-.18 *$ & -.04 & .01 & $.30 * *$ & -.07 & -.04 & .01 & $(.97)$ \\
\hline
\end{tabular}

Note: $N=128$. Ratings of proactive behaviors were provided by participants' supervisors; other variables were provided by self-report. The Cronbach's alpha for each scale is presented on the diagonal. * $p<.05 ; * * p<.01 ; * * *<.001$.

Table 5. Results of hierarchical regression models of the curvilinear effect of positive affect on proactive behaviors (Study 2).

\begin{tabular}{|c|c|c|c|}
\hline \multirow[b]{2}{*}{ Variables } & \multicolumn{3}{|c|}{ Proactive behaviors } \\
\hline & Model 1 & Model 2 & Model 3 \\
\hline Age & $-0.16^{+}$ & $-0.17^{+}$ & $-0.15^{+}$ \\
\hline Gender & -0.03 & -0.02 & -0.02 \\
\hline Years of supervision & 0.00 & 0.01 & -0.02 \\
\hline Familiarity with work & $0.28 * *$ & $0.28 * *$ & $0.29 * *$ \\
\hline Positive affectivity & -0.07 & -0.11 & -0.09 \\
\hline Negative affectivity & -0.00 & 0.01 & -0.02 \\
\hline \multicolumn{4}{|l|}{ Main variables } \\
\hline Positive affect at work (linear) & & 0.10 & -0.02 \\
\hline Positive affect at work (curvilinear) & & & $-0.22 *$ \\
\hline$\triangle F$ & $2.57 * *$ & 0.92 & $4.82 *$ \\
\hline$R^{2}$ & 0.12 & 0.13 & 0.16 \\
\hline
\end{tabular}

Note: $N=128 .{ }^{+} p<.10 ; * p<.05 ; * * p<.01$.

of positive affect at work on proactive behaviors in Step 2. Finally, we entered the squared term of positive affect at work to test its curvilinear effect on proactive behaviors in Step 3. Results of our regression analyses are displayed in Table 5.

In Model 1, supervisor's familiarity with the participants' work was associated with a higher level of supervisorreported proactive behaviors $(\beta=.28, p<.001)$, suggesting that supervisors with greater levels of familiarity with the work of their subordinates were more likely to provide high ratings of proactive behaviors. Interestingly, both positive and negative affectivity were unrelated to ratings of proactivity. This suggests that the experience of positive affect specific to the work context may be a more important explanatory variable in predicting proactivity than individual traits.

In Model 2, we entered the linear term of positive affect and found that it was unrelated to proactive behaviors $(\beta=.10, n s)$. To test for a curvilinear effect of positive affect at work on proactive behaviors, we entered the squared term of positive affect into the regression equation. As shown in Model 3, the squared term of positive affect was significant $(\beta=-.22, p<.05)$. As illustrated in Figure 2, positive affect exhibited an inverted U-shaped relationship with proactive behaviors, suggesting that the inflection point occurs at 5.64 of positive affect (Figure 2). The 


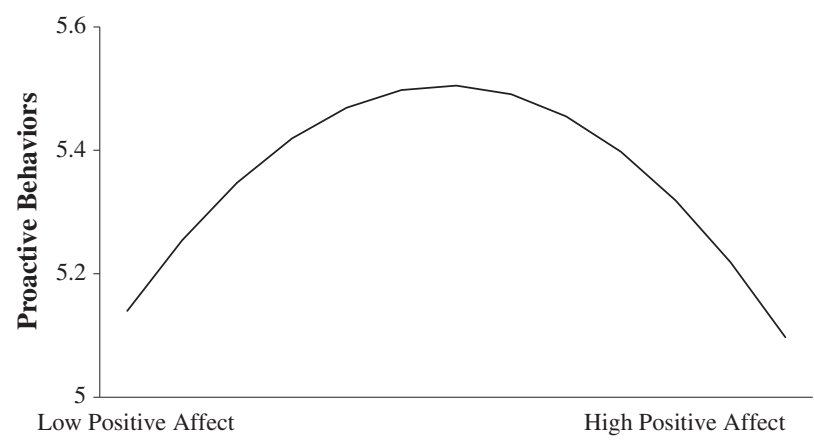

Figure 2. The curvilinear effects of positive affect at work on proactive behaviors (Study 2)

inclusion of the squared term of positive affect into the equation resulted in an improvement of adjusted $R^{2}$ from 0.13 to 0.16 , or an increase of 28.6 percent. $^{2}$

\section{Discussion}

Across two studies in two different industries, we found that positive affect at work exhibits a curvilinear, inverted-U relationship with proactive behaviors, such that levels of proactive behaviors are the highest at an intermediate level of positive affect at work: too little or too high levels of positive affect at work are associated with reduced levels of proactive behaviors.

\section{Theoretical implications}

By demonstrating a curvilinear relationship between positive affect at work and proactivity, we make two noteworthy contributions to the literature. First, our research contributes to the literature on proactivity. Previous research on proactive behaviors has generally shown a positive linear relationship between positive affect and proactive behaviors (Bindl et al., 2012; Bissing-Olson et al, 2013; Den Hartog \& Belschak, 2007; Fritz \& Sonnentag, 2009). In this article, we redirect prior theory that assumes that positive affect is always conducive to proactive behaviors. We do so by theorizing and providing empirical evidence of a curvilinear relationship between positive affect and proactivity. Our results are suggestive that at low levels of positive affect, individuals engage in fewer proactive behaviors because of reduced cognition and behavioral action tendency, and as positive affect at work increases to a moderate level, employees are more likely to engage in proactive behaviors because of the broaden-and-build effect. However, at high level positive affect, employees perceive that things are going well and that they do not need to take proactive steps to change the status quo, resulting in lower levels of proactive behaviors. In sum, the curvilinear pattern found across both studies offers a noteworthy refinement to prior theory and research, which has generally assumed that more positive affect at work should contribute to more proactive behaviors.

\footnotetext{
${ }^{2}$ We also empirically tested whether results would be comparable without controlling for positive and negative affectivity. We found that when positive and negative affectivity are not entered in the equation, the linear term of positive affect is insignificant $(\beta=.06, n s)$, whereas the squared term of positive affect is significant $(\beta=-.22, p<.05)$. In addition, similar to Study 1 , we also tested whether our results would be comparable without controlling for years of supervision and supervisor's familiarity with subordinate's work. We found that when years of supervision and supervisor's familiarity with subordinate's work are not entered in the equation, the linear term of positive affect is insignificant $(\beta=-.01, n s)$, whereas the squared term of positive affect is significant $(\beta=-.20, p<.05)$.
} 
Second, our findings also contribute to the burgeoning literature on positive organizational behavior (Luthans, 2002) and positive organizational scholarship in general (Cameron, Dutton, \& Quinn, 2003). Concepts such as thriving (Porath et al., 2012), positive identity (Dutton, Roberts, \& Bednar, 2010), psychological capital (Luthans, Avolio, Avey, \& Norman, 2007), vigor (Shirom, 2003), and work engagement (Schaufeli, Martinez, Pinto, Salanova, \& Bakker, 2002) on an individual level as well as productive energy (Cole, Bruch, \& Vogel, 2012), compassion organizing (Lilius, Worline, Dutton, Kanov, \& Maitlis, 2011), and organizational virtuousness (Cameron, Bright, \& Caza, 2004) on an organizational level have proliferated in recent years (Cameron \& Spreitzer, 2012). A common assumption across these streams of literatures is the more-is-better notion: more individual thriving is better for task performance (Porath et al., 2012), more work engagement is better for contextual performance (Christian, Garza, \& Slaughter, 2011), and more organizational virtuousness is better for firm performance (Cameron et al., 2004). While our intention is not to discount the importance of positivity in the workplace, our findings contribute to the growing literature on positive organizational behavior by providing a more balanced point of view about the role of positivity in the workplace. In this study, we extend research on positive organizational behavior and positive organizational scholarship by providing evidence that too much positive affect at work can be detrimental for proactive behaviors. The argument is that employees with very high levels of positive affect at work will see less necessity for change, as high positive affect serves as a signal that the work environment is in good shape and not in need of major improvements. Indeed, our finding corroborates with recent commentary suggesting that there can be indeed too much of a good thing (Grant \& Schwartz, 2011; Pierce \& Aguinis, 2013).

\section{Strengths and limitations}

The design of our studies offers several methodological strengths. Past studies linking positive affect and proactive behaviors are often troubled by common method bias (e.g., Warr, Bindl, Parker, \& Inceoglu, 2013). In both studies, we invited participants' supervisors to provide ratings of proactive behaviors to avoid common method bias (Podsakoff, MacKenzie, Lee, \& Podsakoff, 2003) and found a more nuanced relationship between positive affect and proactivity than previously assumed. In addition, the two different samples we collected data from contribute to the generalizability of our findings. Specifically, we find the same inverted-U relationship between positive affect at work and proactive behaviors despite differences in industry and organization. It will be interesting for future research to examine whether relationships between positive affect at work and proactive behaviors differ depending on who reports proactive behaviors (self-rated vs. supervisor-rated).

Notwithstanding these strengths, several limitations should be noted. First, in both studies, we used subjective vitality at work as a measure of positive affect at work; however, it is possible to use other measures of emotion (e.g., Positive Affect and Negative Affect Scale; Watson et al., 1988) with a work referent. In addition, we have no way of knowing whether participants responded with only work-related positive affect. This concern is somewhat mitigated in that bivariate correlations in Study 2 revealed that positive and negative affectivity as individual traits are moderately but not completely associated with positive affect at work, suggesting that participants are able to distinguish between their general feelings and their positive affect at work. We encourage future research to use other established measures with different methodologies (e.g., diary survey) to further dissect the curvilinear relationship between positive affect at work and proactive behaviors.

Second, we recognized that selection bias is a possible limitation of the current study, especially in Study 1 in which those who eventually took part in our study exhibited greater levels of subjective vitality and proactive behaviors than those who did not respond to our survey. It is possible that those who did not participate in Study 1 at all were those who were lower on positive affect and who were less proactive themselves. Thus, it is likely that we are missing participants who are low on positive affect and proactive behaviors (which would not threaten our claim of a curvilinear relationship), and not those who are high on positive affect and high on proactive behaviors (which would threaten our claim of a curvilinear relationship). Therefore, we believe that even if those low on positive affect 
and low on proactive behaviors did not participate, the curvilinear relationship remains intact. Furthermore, we replicated the curvilinear findings from Study 2 (with a very high response rate), and thus, we are more confident that our sample in Study 1 did not suffer from selection bias. Still, we encourage future research to use multiple methods and strategies to enhance response rate, such as incentives (Church, 1993), use of a university sponsor (Greer, Chuchinprakam, \& Seshadri, 2000), limiting the number of items on a survey, or promise of a summary report (Bednar \& Westphal, 2006).

Third, we note that the current study tested the influence of positive affect at work on proactive behaviors using a one-month time lag. Although such a time lag is not uncommon (e.g., Bindl et al., 2012, Study 2), we note that future research may use an experience sampling technique to investigate the immediate effects of positive affect at work on proactive behaviors. However, the time-frame chosen in Study 2 might be justified as our informal interviews suggest that-at least in this particular sample-proactive behaviors do not take place on a daily or weekly basis. Still, future research will benefit from employing experience sampling or day-level research techniques to better elucidate the effect of positive affect at work on proactive behaviors.

Finally, it is important to note that we did not use a standardized measure of proactive behaviors in Study 2. Although the generalizability of our findings is somewhat limited as a result, there are several reasons why we believe that our tailored measure of proactive behaviors is of high quality. First, before data collection took place, we noted that potential participants in Study 2 occupied supervisory role in the organization. Therefore, we performed several interviews with our key informants to explore the types of proactive behaviors they performed as a supervisor. Second, we adapted measures from the existing literature to better gauge the types of proactive behaviors that participants performed in their specific work context. Third, we asked expert raters to judge the relevance of our items and retained items that were consistent with the definition of proactive behaviors. Finally, we note that our findings are consistent with those of Study 1, which used an established measure. Therefore, we feel confident of the curvilinear relationship between positive affect at work and proactive behaviors. Still, future research may use standardized measures of proactive behaviors such as Raub and Liao's (2012) measure of customer-focused proactive behaviors to increase the generalizability of our finding.

\section{Practical implications}

Our findings have important practical implications. First, like past research demonstrating the linkage between positive affect and proactive behaviors (Bindl et al., 2012), our research suggests that there are values in enhancing employees' feeling of positive affect. Past research indeed suggests that organizational leaders can enhance employees' positive affect by enhancing leader's transformational characteristics (Bono, Foldes, Vinson, \& Muros, 2007), providing opportunities for recovery both during work (Trougakos, Beal, Green, \& Weiss, 2008) and after work (Sonnentag, Binnewies, \& Mojza, 2008), enhancing employees' feeling of energy through providing autonomy, sense of competence, and belongingness (Quinn, Spreitzer, \& Lam, 2012), and providing support to manage work-family conflict (Rothbard, 2001). Second, and perhaps more intriguingly, supervisors should also be keenly aware of situations when their employees feel overly positive. When their levels of positive affect at work are too high, they may find their ability to focus and to exert additional effort and their motivation for proactive behaviors impaired. Organizational practices that generate high levels of subjective energy such as the use of games (Mollick \& Rothbard, 2013), parties (Dumas, Phillips, \& Rothbard, 2013), and dependence on social networking like Facebook and Twitter (Rothbard, Berg, \& Ollier-Malaterre, 2013) may have unexpected consequences on proactive behaviors if positive affect levels are raised too much. Rather than creating focus and channeling attention, such high levels of positive affect may act as distraction hindering engagement in proactive behaviors at work. 


\section{Conclusion}

Our studies offer new insights into the relationship between positive affect and proactive behaviors at work. We find that rather than a simple linear relationship, the relationship seems to be curvilinear such that too much and too little positive affect at work results in lower levels of proactive behaviors. Thus, we offer evidence that challenges the "more is better" assumption commonly associated with positive affect in the workplace.

\section{Author biographies}

Dr. Chak Fu Lam is an assistant professor of Management \& Entrepreneurship at Sawyer School of Business at Suffolk University. His research focuses on employee voice, proactive behaviors, and citizenship behaviors.

Dr. Gretchen Spreitzer is the Keith E. and Valerie J. Alessi Professor of Business Administration at the Ross School of Business at the University of Michigan. She is also the co-director of the Ross Leadership Initiative. Her research focuses on employee empowerment and leadership development, particularly within a context of organizational change and decline. Her most recent research is examining how organizations can enable thriving.

Dr. Charlotte Fritz is an assistant professor in Industrial and Organizational Psychology at Portland State University. Her research focuses on how to keep employees happy, healthy, and productive. Specifically, in her research, she examines processes related to stress in the workplace, recovery from work, and work-life balance.

\section{References}

Aiken, L. S., \& West, S. G. (1991). Regression: Testing and interpreting interactions. Thousand Oaks, CA: Sage.

Ashford, S. J., \& Black, J. S. (1996). Proactivity during organizational entry: The role of desire for control. Journal of Applied Psychology, 81(2), 199-214.

Ashford, S. J., \& Cummings, L. L. (1983). Feedback as an individual resource: Personal strategies of creating information. Organizational Behavior and Human Performance, 32(3), 370-398.

Ashford, S. J., Rothbard, N. P., Piderit, S. K., \& Dutton, J. E. (1998). Out on a limb: The role of context and impression management in selling gender-equity issues. Administrative Science Quarterly, 43(1), 23-57.

Bednar, M. K., \& Westphal, J. D. (2006). Surveying the corporate elite: Theoretical and practical guidance on improving response rates and response quality in top management survey questionnaires. In D. Ketchen, Jr., \& D. Bergh (Eds.), Research methodology in strategy and management (Vol. 3, pp. 37-56). New York: JAI Press.

Bindl, U. K., Parker, S. K., Totterdell, P., \& Hagger-Johnson, G. H. (2012). Fuel of the self-starter: How mood relates to proactive goal regulation. Journal of Applied Psychology, 97(1), 134-150.

Bissing-Olson, M., Iyer, A., Fielding, K. S., \& Zacher, H. (2013). Relationships between daily affect and proenvironmental behavior at work: The moderating role of pro-environmental attitude. Journal of Organizational Behavior, 34(2), 156-175.

Bono, J., Foldes, H. J., Vinson, G., \& Muros, J. P. (2007). Workplace emotions: The role of supervision and leadership. Journal of Applied Psychology, 92(5), 1357-1367.

Cameron, K., \& Spreitzer, G. (2012). Oxford handbook of positive organizational scholarship. New York, NY: Oxford University Press.

Cameron, K. S., Bright, D., \& Caza, A. (2004). Exploring the relationships between organizational virtuousness and performance. American Behavioral Scientist, 47(6), 766-790.

Cameron, K. S., Dutton, J. E., \& Quinn, R. E. (2003). Positive organizational scholarship: Foundations of a new discipline. San Francisco: Berrett-Koehler.

Carver, C. S. (2003). Pleasure as a sign you can attend to something else: Placing positive feelings within a general model of affect. Cognition and Emotion, 17(2), 241-261.

Christian, M. S., Garza, A. S., \& Slaughter, J. E. (2011). Work engagement: A quantitative review and test of its relations with task and contextual performance. Personnel Psychology, 64(1), 89-136.

Church, A. H. (1993). Estimating the effect of incentives on mail survey response rates: A meta-analysis. Public Opinion Quarterly, 57, 62-79. 
Clore, G. L., Schwarz, N., \& Conway, M. (1994). Affective causes and consequences of social information processing. In R. S. Wyer, \& T. K. Srull (Eds.), Handbook of social cognition (2nd edn, Vol. 1, pp. 323-417). Hillsdale, NJ: Erlbaum.

Cole, M. S., Bruch, H., \& Vogel, B. (2012). Energy at work: A measurement validation and linkage to unit performance. Journal of Organizational Behavior, 33(4), 445-467.

Crant, J. M. (2000). Proactive behavior in organizations. Journal of Management, 26(3), 435-462.

Den Hartog, D. N., \& Belschak, F. D. (2007). Personal initiative, commitment and affect at work. Journal of Occupational and Organizational Psychology, 80(4), 601-622.

Derryberry, D., \& Tucker, D. M. 1994. Motivating the focus of attention. In P. M. Niedenthal, \& S. Kitayama (Eds.), The heart's eye: Emotional influences in perception and attention (pp. 167-196). San Diego, CA: Academic Press.

Dumas, T., Phillips, K. W., \& Rothbard, N. (2013). Getting closer at the company party: Integration experiences, racial dissimilarity, and workplace relationships. Organization Sciences, 24(5), 1377-1401. DOI:10.1287/orsc.1120.0808

Dutton, J. E., \& Ashford, S. J. (1993). Selling issues to top management. Academy of Management Review, 18(3), $397-428$.

Dutton, J. E., Roberts, L. M., \& Bednar, J. (2010). Pathways for positive identity construction at work: Four types of positive identity and the building of social resources. Academy of Management Review, 35(2), 265-293.

Foo, M., Uy, M. A., \& Baron, R. A. (2009). How do feelings influence effort? An empirical study of entrepreneurs' affect and venture effort. Journal of Applied Psychology, 94(4), 1086-1094.

Fredrickson, B. L. (1998). What good are positive emotions. Review of General Psychology, 2(3), 300-319.

Fredrickson, B. L. (2001). The role of positive emotions in positive psychology: the broaden-and-build theory of positive emotions. American Psychologist, 56(3), 218-226.

Fredrickson, B. L. (2013, July 15). Updated thinking on positivity ratios. American Psychologist. Advance online publication. DOI:10.1037/a0033584

Fredrickson, B. L., Cohn, M. A., Coffey, K. A., Pek, J., \& Finkel, S. M. (2008). Open hearts build lives: Positive emotions, induced through loving-kindness meditation, build consequential personal resources. Journal of Personality and Social Psychology, 95(5), 1045-1062.

Frese, M., \& Fay, D. (2001). Personal initiative: An active performance concept for work in the 21 st century. In B. W. Staw, \& R. L. Sutton (Eds.), Research in organizational behavior (Vol. 23, pp. 133-187). Stambord, CT: JAI Press.

Frese, M., Fay, D., Hilburger, T., Leng, K., \& Tag, A. (1997). The concept of personal initiative: Operationalization, reliability and validity in two German samples. Journal of Occupational and Organizational Psychology, 70(2), $139-161$.

Frese, M., Krauss, S. I., Keith, N., Escher, S., Grabarkiewicz, R., Luneng, S. T., .. Friedrich, C. (2007). Business owners' action planning and its relationship to business success in three African countries. Journal of Applied Psychology, 92(6), 1481-1498.

Fritz, C., \& Sonnentag, S. (2009). Antecedents of day-level proactive behavior: A look at job stressors and positive affect during the workday. Journal of Management, 35(1), 94-111.

Fritz, C., Lam, C. F., \& Spreitzer, G. M. (2011). It's the little things that matter: An examination of knowledge workers' energy management. Academy of Management Perspectives, 25(3), 28-39.

Grant, A. M., \& Ashford, S. J. (2008). The dynamics of proactivity at work. Research in Organizational Behavior, $28,3-34$.

Grant, A. M., \& Parker, S. K. (2011). Redesigning work design theories: The rise of relational and proactive perspectives. Academy of Management Annals, 3, 317-375.

Grant, A. M., \& Schwartz, B. (2011). Too much of a good thing: The challenge and opportunity of the inverted U. Perspectives on Psychological Science, 6(1), 61-76.

Grant, A. M., Parker, S., \& Collins, C. (2009). Getting credit for proactive behavior: Supervisor reactions depend on what you value and how you feel. Personnel Psychology, 62(1), 31-55.

Greer, T. V., Chuchinprakam, N., \& Seshadri, S. (2000). Likelihood of participating in mail survey research: Business respondents' perspective. Industrial Marketing Management, 29, 97-109.

Griffin, M. A., Neal, A., \& Parker, S. K. (2007). A new model of work role performance: Positive behavior in uncertain and interdependent contexts. Academy of Management Journal, 50(2), 327-347.

Heckman, J. J. (1979). Sample selection bias as a specification error. Econometrica, 47(1), 153-161.

Kaplan, S., Bradley, J. C., Luchman, J. N., \& Haynes, D. (2009). On the role of positive and negative affectivity in job performance: A meta-analytic investigation. Journal of Applied Psychology, 94(1), 162-176.

Kimchi, R. (1992). Primacy of wholistic processing and global/local paradigm: A critical review. Psychological Bulletin, 112(1), 24-38.

Lam, C. F., \& Mayer, D. M. (in press). When do employees speak up for their customers? A model of voice in a customer service context. Personnel Psychology. DOI:10.1111/peps.12050

Lilius, J. M., Worline, M. C., Dutton, J. E., Kanov, J. M., \& Maitlis, S. (2011). Understanding compassion capability. Human Relations, 64(7), 873-899.

Luthans, F. (2002). The need for and meaning of positive organizational behavior. Journal of Organizational Behavior, 23(6), 596-706.

Luthans, F., Avolio, B. J., Avey, J. B., \& Norman, S. M. (2007). Positive psychological capital: Measurement and relationship with performance and satisfaction. Personnel Psychology, 60(3), 541-572. 
Martin, L., Friedman, H., Tucker, J., TomlinsonKeasey, C., Criqui, M., \& Schwartz, J. (2002). A life course perspective of childhood cheerfulness and its relation to mortality risk. Personality and Social Psychology Bulletin, 28(9), 1155-1165.

Mollick, E., \& Rothbard, N. (2013). Mandatory fun: Gamification and the impacts of games at work. (Working paper).

Morrison, E. W., \& Phelps, C. C. (1999). Taking charge at work: Extra-role efforts to initiate workplace change. Academy of Management Journal, 42(4), 403-419.

Nix, G. A., Ryan, R. M., Manly, J. B., \& Deci, E. L. (1999). Revitalization through self-regulation: The effects of autonomous and controlled motivation on happiness and vitality. Journal of Experimental Social Psychology, 35(3), $266-284$.

Oishi, S., Diener, E., \& Lucas, R. (2007). The optimal level of well-being. Perspectives on Psychological Science, 2(4), 346-360.

Parker, S. K., \& Wu, C. (in press). Leading for proactivity: How leaders cultivate staff who make things happen. In D. Day (Ed.), The Oxford handbook of leadership and organizations. Oxford: Oxford University Press.

Parker, S. K., Bindl, U. K., \& Strauss, K. (2010). Making things happen: A model of proactive behavior. Journal of Management, 36(4), 827-856.

Parker, S. K., Wall, T. D., \& Jackson, P. R. (1997). “That's not my job”: Developing flexible employee work orientation. Academy of Management Journal, 40(4), 899-929.

Parker, S. K., Williams, H. M., \& Turnver, N. (2006). Modeling the antecedents of proactive behavior at work. Journal of Applied Psychology, 91(3), 636-652.

Pierce, J. R., \& Aguinis, H. (2013). The too-much-of-a-good-thing effect in management. Journal of Management, 39, $313-338$.

Podsakoff, P. M., MacKenzie, S. B., Lee, J., \& Podsakoff, N. (2003). Common method biases in behavioral research: A critical review of the literature and recommended remedies. Journal of Applied Psychology, 88(5), 879-903.

Porath, C., Spreitzer, G., Gibson, C., \& Garnett, F. (2012). Thriving at work: Towards its measurement, construct validation, and theoretical refinement. Journal of Organizational Behavior, 33(2), 250-275.

Quinn, R., Spreitzer, G. M., \& Lam, C. F. (2012). Building a sustainable model of human energy in organizations: Exploring the critical role of resources. The Academy of Management Annals, 6(1), 1-60.

Raub, S., \& Liao, H. (2012). Doing the right thing without being told: Joint effects of initiative climate and general self-efficacy on employee proactive customer service performance. Journal of Applied Psychology, 97(3), 651-667.

Rego, A., Sousa, F., Marqes, C., \& Cunah, M. P. 2012. Optimism predicting employees' creativity: The mediating role of positive affect and the positivity ratio. European Journal of Work and Organizational Psychology, 21(2), 244-270.

Rothbard, N. P. (2001). Enriching or depleting? The dynamics of engagement in work and family roles. Administrative Science Quarterly, 46(4), 655-684.

Rothbard, N., Berg, J., \& Ollier-Malaterre, A. (2013). OMG my boss just friended me: Boundary management and the role of hierarchy, disclosure, and gender in online social networking. (Working paper).

Ryan, R. M., \& Frederick, C. M. (1997). On energy, personality and health: Subjective vitality as a dynamic reflection of wellbeing. Journal of Personality, 65(3), 529-565.

Schaufeli, W. B., Martinez, I. M., Pinto, A. M., Salanova, M., \& Bakker, A. B. (2002). Burnout and engagement in university students. Journal of Cross-Cultural Psychology, 33(5), 464-481.

Schwarz, N. (1990). Feelings as information: Informational and motivational functions of affective states. In E. T. Higgins, \& R. M. Sorrentino (Eds.), Handbook on motivation and cognition (Vol. 2, pp. 527-561). New York: Guilford Press.

Schwarz, N., \& Clore, G. (1983). Mood, misattribution, and judgments of well-being: Informative and directive functions of affective states. Journal of Personality and Social Psychology, 45(3), 513-523.

Schwarz, N., \& Clore, G. L. (2003). Mood as information: 20 years later. Psychological Inquiry: An International Journal for the Advancement of Psychological Theory, 14(3-4), 296-303.

Seibert, S. E., Kraimer, M. L., \& Crant, J. M. (2001). What do proactive people do? A longitudinal model linking proactive personality and career success. Personnel Psychology, 54(3), 845-874.

Shaffer, J. A., \& Postlethwaite, B. E. (2012). A matter of context: A meta-analytic investigation of the relative validity of contextualized and noncontextualized personality measures. Personnel Psychology, 65(3), 445-494.

Shirom, A. (2003). Feeling vigorous at work? The construct of vigor and the study of positive affect in organizations. In D. Ganster \& P. L. Perrewe, (Eds.), Research in organizational stress and well-being (Vol. 3, pp. 135-164). Greenwich, CN: JAI Press.

Sonnentag, S. (2003). Recovery, work engagement, and proactive behavior: A new look at the interface between nonwork and work. Journal of Applied Psychology, 88(3), 518-528.

Sonnentag, S., Binnewies, C., \& Mojza, E. J. (2008). "Did you have a nice evening?" A day-level study on recovery experiences, sleep, and affect. Journal of Applied Psychology, 93(3), 674-684.

Stajkovic, A. D., \& Luthans, F. (1998). Self-efficacy and work-related performance: A meta-analysis. Psychological Bulletin, 124, 240-261.

Tangirala, S., \& Ramanujam, R. (2008). Exploring nonlinearity in employee voice: The effects of personal control and organizational identification. Academy of Management Journal, 51(6), 1189-1203. 
Trougakos, J. P., Beal, D. J., Green, S. G., \& Weiss, H. M. (2008). Making the break count: An episodic examination of recovery activities, emotional experiences, and positive affective displays. Academy of Management Journal, 51(1), $131-146$.

Van Dyne, L., \& LePine, J. A. (1998). Helping and voice extra-role behaviors: Evidence of construct and predictive validity. Academy of Management Journal, 41(1), 108-119.

Warr, P., Bindl, U. K., Parker, S. K., \& Inceoglu, I. (2013). Four-quadrant investigation of job-related affects and behaviours. European Journal of Work and Organizational Psychology, DOI:10.1080/1359432X.2012.744449.

Watson, D., Clark, L. A., \& Tellegen, A. (1988). Development and validation of brief measures of positive and negative affect: The PANAS scales. Journal of Personality and Social Psychology, 54(6), 1063-1070.

Waugh, C. E., \& Fredrickson, B. L. (2006). Nice to know you: Positive emotions, self-other overlap, and complex understanding in the formation of a new relationship. Journal of Positive Psychology, 1(2), 93-106.

Weinstein, N. D. (1980). Unrealistic optimism about susceptibility to health problems. Journal of Behavioral Medicine, 5(4), 441-460.

Weinstein, N. D., \& Klein, W. M. (1996). Unrealistic optimism: Present and future. Journal of Social and Clinical Psychology, 15(1), 1-8.

Whiting, S. W., Maynes, T. D., Podsakoff, N. P., \& Podsakoff, P. M. (2012). Effects of message, source, and context on evaluations of employee voice behavior. Journal of Applied Psychology, 97, 159-182.

\section{Appendix A}

\section{Proactive Behaviors Scale (Study 2)}

1. He/she actively looked for customer service concerns.

2. He/she looked for feedback from the customers to see if there were any problems.

3. He/she tried to correct faulty customer service processes before they became problems.

4. He/she tried to fix problems before customers even noticed.

5. He/she anticipated customer service concerns before they were noticed by others.

6. He/she took the initiative in identifying customer service problems.

7. He/she tried to learn from other departments about how we were doing to make sure there were no complaints.

8. He/she asked for feedback about customer service issues from those in other departments. 